\title{
ORIGINAL ARTICLE A study of level of Depression, Anxiety and Life Satisfaction in Acute and Chronic Schizophrenia
}

\author{
Ranjan Kumar, D. K. Kenswar* \\ Department of Clinical Psychology, LGBRIMH, Tezpur, Assam, * Department of Clinical Psychology, \\ RINPAS, Kanke, Ranchi-834006.
}

\begin{abstract}
Background: The present study focuses upon studying the level of depression, anxiety and life satisfaction in acute and chronic schizophrenics. Schizophrenia is known to be a heterogeneous disorder characterized by positive symptoms, negative symptoms, disorganized state and cognitive deficits. Acute schizophrenia is a disorder consisting of various degrees of psychosis, characterized by the sudden onset of personality disorganization
\end{abstract}

Methods: Thirty acute and thirty chronic schizophrenic patients were taken within the age range of 18 to 55 years of male sex only. A self developed socio-demographic and clinical data sheet was used to assess the socio-demographic correlates. The Beck Depression Inventory (BDI), the Hindi Version of Cattell's Self Analysis Form or IPAT Anxiety Scale Questionnaire (A.S.Q) and the Life Satisfaction Scale were used to assess the levels of depression, anxiety and life satisfaction respectively.

Results: Significant differences were found between Acute and Chronic Schizophrenics in depression which was due to the four factors: Sense of Failure, Crying Spells, Social Withdrawal, and in Work Inhibition. No significant differences were found in anxiety (both covert and overt). On Life satisfaction, in the acute and chronic schizophrenia groups, the level of life satisfaction is more among the acute schizophrenia group in comparison to chronic schizophrenia group.

Conclusion: The acute schizophrenia group appears to be having relatively higher level of depression than as compared to the chronic group. But at the same time the acute group seems to have better life satisfaction than the chronic schizophrenia group.

\section{INTRODUCTION}

Schizophrenia is known to be a heterogeneous disorder characterized by positive symptoms, negative symptoms, disorganized state and cognitive deficits. The schizophrenia disorders are characterized in general by fundamental and characteristic disorders of thinking and perception, and by inappropriate or blunted affect.

Acute schizophrenia is a disorder consisting of various degrees of psychosis, characterized by the sudden onset of personality disorganization. Symptoms include disturbances in thought, mood, and behavior. Positive symptoms include delusions, hallucinations, especially auditory; disorganized speech; inappropriate affect; and disorganized behavior.

The common signs of chronic schizophrenia are social withdrawal, under activity, depression and odd behavior. These symptoms are often known as 'negative' symptoms and hallucinations and delusions are also common. Sometimes in chronic schizophrenia, the person appears to become used to these disordered thoughts.

\section{Schizophrenia and Depression:}

The individual experiencing depression is deeply unhappy and finds little pleasure in life. This state is accompanied by at least some of the following: increased 
or decreased sleep, increased or decreased appetite, loss of interest in sex, loss of energy or excessive energy, difficulties concentrating and making decision, and sometimes suicidal thinking and actual attempts. Depressive symptomatology as a feature of schizophrenia has been recognized since Bleuler first introduced the term in 1908. He described depressive symptoms as either directly triggered by the disease process in the acute stages or occurring as secondary symptoms.

Knights and Hirsch (1981) ${ }^{1}$ found depressive symptoms in nearly two thirds of patients admitted with schizophrenia, and Johnson ascertained that 70 per cent of a sample of 30 subjects with schizophrenia had a depressive episode over a two year period. Depression may occur independently of the symptoms of schizophrenia and several months after recovery from an acute episode, i.e., post-psychotic depression, in up to 30 per cent of cases. Many investigators have examined the prevalence of depression at different phases of the schizophrenic illness. In particular, Knights and Hirsch (1981) found depressive symptoms in nearly two thirds of patients admitted with schizophrenia, and Johnson ascertained that 70 per cent of a sample of 30 subjects with schizophrenia had a depressive episode over a two year period. Depression may occur independently of the symptoms of schizophrenia and several months after recovery from an acute episode, i.e., post-psychotic depression, in up to 30 per cent of cases. A similar rate of depression was found in the longitudinal study of Birchwood et al $(2000)^{2}$ who found no significant associations between depressive symptomatology and negative schizophrenia symptoms. Tarrier et al. (1991) concluded from their analysis of prodromal symptoms that psychotic relapses can be predicted in 75 per cent of cases on the basis of increasing scores for hallucinations and depressive symptoms in the two months preceding a relapse.

The character of depression in acute schizophrenia was examined by Leff et al. $(1988)^{3}$ found that the full spectrum of depressive symptoms was present in varying proportions in their group of drug-free acutely ill schizophrenic patients. In the majority of cases, the psychotic and depressive symptoms followed a similar time course.

Depression is an integral feature of schizophrenia; during the prodromal phase or the first episode of schizophrenia and the major risk factor for suicide among patients with schizophrenia. It is generally acknowledged that depressive symptoms represent an important and distinct symptoms domain in schizophrenia. Mood state, energy loss, impaired concentration and reduced self-confidence are depressive dimensions that materially contribute to the loss of social and vocational capacity experienced by schizophrenic subjects, thus reducing their quality of life. The importance and severity of depression in schizophrenia is sustained by the high $10-15 \%$ rate of suicide, which is the leading cause of premature death among schizophrenics. Some authors suggest that depressive symptoms may be related to schizophrenia when the full-blown psychosis is most evident (socalled "revealed depression") ${ }^{4}$, thus suggesting that the depression may be associated with the psychotic state itself or a subjective reaction to the experience of psychotic decomposition.

\section{Schizophrenia and Anxiety:}

Anxiety is a construct and used to explain behavior. It refers to a subjective experience of the individual a "painful uneasiness state of mind" (Webster's Dictionary, 1960). Sigmund Freud first conceptualized anxiety neurosis in 1895 and his position was that neurotic anxiety resulted from the discharge of repressed libido, his term for accumulated somatic sexual tension. He later enlarged his view to relate anxiety to the conflict between the ego and the id, between mediation with reality and instinctual drives. Later on, he modified this view and conceived it as a signal indicating the presence of a danger situation and differentiated between "objective anxiety", "neurotic anxiety" and "moral anxiety" largely on the basis of whether the source of the danger was from the external world or from the internal impulses. 
Strian et al. ${ }^{5}$ describes the prevalence and distribution of anxiety symptomatology and anxiety disorders in a sample of hospitalized patients with schizophrenia, the estimated level of agreement between a clinician diagnostic measure and anxiety symptom status measures, and their internal consistency based on the average inter item correlations. Seventy inpatients receiving treatment for schizophrenia were assessed before discharge using a face-to-face diagnostic interview and structured questionnaires, namely the Mini International Neuropsychiatric Interview, the Hospital Anxiety and Depression Scale, the Hamilton Anxiety Scale, the Spielberger Anxiety Inventory, and the Stein Generalized Anxiety Disorder (GAD) Scale. About a quarter of patients met criteria for an anxiety disorder, with GAD and social phobia occurring most commonly. There was poor agreement between the Mini International Neuropsychiatric Interview and a diagnosis of anxiety based on symptom status measures. The Stein GAD scale demonstrated the highest internal consistency $(0.85)$ followed by the Hamilton Anxiety Scale (0.76). Anxiety disorders and anxiety symptomatology are highly prevalent in schizophrenia.

\section{Schizophrenia and Life Satisfaction:}

Life satisfaction is one of the indicators of subjective wellbeing. It has been conceptualized as an assessment of life as a whole the basis of the fit between personal goals and achievements. Life satisfaction is a particular effective predictor of psychiatric morbidity .It is not surprising that life dissatisfaction is much more common in psychiatric patient than in the general population regardless of the level of psychopathology.

For the chronically mentally ill with schizophrenia, the concept of life quality differs from that used to describe physical and less-debilitating psychiatric illnesses. People who are chronically ill with schizophrenia have particular needs that exert a profound influence on their existence and subjective well-being. These patients must deal with the stigma associated with a mental illness.
Persons with schizophrenia usually rate their life satisfaction higher than persons with other psychiatric disorders. Among patients with schizophrenia, severity of psychopathology, especially the non negative symptoms, correlates negatively with subjective life satisfaction but not with objective aspect quality of life. Schizophrenic disorders impose severe hardships on patients and their families and challenge society in the development of public policies that both preserve the public welfare and afford patients a decent quality of life.

\section{METHOD}

\section{Objectives of the study:}

1. To study the severity of depression level in acute and chronic schizophrenics.

2. To study the level of anxiety in acute and chronic schizophrenics.

3. To study the level of life satisfaction in acute and chronic schizophrenics.

\section{Hypotheses:}

1. There is no significant difference between level of depression in acute and chronic schizophrenics.

2. There is no significant difference between level of anxiety in acute and chronic schizophrenics.

3 . There is no significant difference between level of life satisfaction in acute and chronic schizophrenics.

\section{Sample of the study:}

The sample consisted of 30 male acute schizophrenic patients and 30 male chronic schizophrenic patients. All the subjects were selected from the Ranchi Institute of Neuro Psychiatry and Allied Sciences, Kanke, Ranchi. The purposive sampling technique was used in the selection of the sample.

\section{Inclusion criteria:}

- Patient who are diagnosed as schizophrenic patients according to ICD - 10 diagnostic criteria for research. 
- Duration at least 2 years or more than 2 years. (For chronic Schizophrenic patients).

- Duration less than 6month (For acute schizophrenic patients).

- Patients who are in the age range of 18 to 55 years.

\section{Exclusion criteria:}

- Patient's with active psychopathology.

- History of severe physical illness in near past.

- History of alcohol or substance abuse.

- Psychopathology that was interfering in eliciting reliable information.

\section{Tools for assessment:}

Personal and Clinical Data Sheet was used to gather information like name, age, sex, education, religion, marital status, age and mode of onset, course and duration of illness etc.

Beck Depression Inventory (BDI, developed by A.T. Beck (1961) was used for assessing the level of depression present among the acute and chronic schizophrenic group. is a 21 item Scale, in which evaluates key symptoms of depression including mood, pessimism, sense of failure, self-dissatisfaction, guilt punishment, self-dislike, self-accusation, suicidal ideas, crying, irritability, social withdrawal, indecisiveness, body image change, work-difficulty, insomnia, and fatigability, loss of appetite, weight loss, somatic preoccupation, and loss of libido. Individuals are asked to rate themselves on a 0 to 3 spectrum (0-least, 3most) with a score range 0 to 63 . Total Score is a sum of all items. The most recent guideline suggests the following interpretation of severity of score: 0-9, minimal; 10-16, mild; 17-29 moderate; and 30-63, severe. Subscale scores may be calculated for a cognitive-affective factor and a somatic- performance factor.

\footnotetext{
Hindi Version of Cattell's Self Analysis Form or IPAT Anxiety Scale Questionnaire (A.S.Q) was originally developed by R.B. Cattell in 1963; translated
}

and adopted by permission into Hindi and printed and published in India by Dr. S.D. Kapoor in 1970 and introduced as 'Self Analysis Form'. IPAT Anxiety scale is a 40 items scale which evaluates key symptoms of anxiety, including two types of anxiety; first is covert and second is overt anxiety. As so far, scoring is concerned the scorer simply adds 2 and 1 for each answer. The higher score always means more anxiety.

Life Satisfaction Scale has been developed by Q.G.Alam and Dr. Ramji Srivastava, $2001^{6}$. This is 60 items related to six areas, viz., Health, Personal, Economic, Marital, Social and Job. The scale has 60 items. Every item is to be responded either in yes or no and yes responses indicate the satisfaction. Every, 'yes' response is assigned 1 mark. The sum of marks is obtained for the entire score.

Procedure of the study: 30 acute schizophrenic patients and 30 chronic schizophrenic patients were selected from RINPAS, Kanke, Ranchi, who was fulfilling the inclusion criteria of the study, constituted the sample. Individual settings were arranged with all selected patients. Beck Depression Inventory, IPATanxiety Scale and Life Satisfaction Scale were administered on them according to the all procedure given in the manual. Each individual session took approximately two hours to complete.

\section{Statistical analysis:}

The obtained data was analyzed using frequency, percentage and chi-square test.

\section{Results and discussion:}

The study was carried out in the month of October 2008 to February 2009. The study was carried out in the month of October 2008 to February 2009.

Table A. Distribution of the sample

\begin{tabular}{|l|l|l|l|}
\hline Sl. No. & Groups & N & Total \\
\hline 1 & Acute Schizophrenics & 30 & 60 \\
\hline 2 & Chronic Schizophrenics & 30 & \\
\hline
\end{tabular}


The groups, the chronic schizophrenic and the acute schizophrenic group were matched in terms of sample size and socio-demographic domains.

Table B1: Level of depression in Acute \& Chronic Schizophrenia

\begin{tabular}{|l|l|l|l|l|l|}
\hline \multirow{3}{*}{ Group } & \multicolumn{5}{|c|}{ Level of Depression } \\
\cline { 2 - 6 } & Minimal & Mild & Moderate & Severe & $\begin{array}{l}\text { Chi- } \\
\text { square }\end{array}$ \\
\cline { 2 - 6 } Acute & $5(16.66 \%)$ & $11(36.66 \%)$ & $12(40 \%)$ & $2(6.66 \%)$ & 15.162, \\
\hline Chronic & $10(33.33 \%)$ & $5(16.66 \%)$ & $11(36.66 \%)$ & $4(13.33 \%)$ & S** \\
\hline
\end{tabular}

$\mathrm{S}^{* *}=$ significant at .01 level

The above table shows that there is significant difference between acute and chronic Schizophrenics group in so far depression is concerned.

It has been found that in acute Schizophrenia group, $83.33 \%$ are having mild to severe level of depression and in chronic Schizophrenia group $66.66 \%$ are having mild to severe level of depression which reflects that among acute schizophrenia patients the depression is high in comparison to that in chronic schizophrenia.

In a cohort study carried out with the Beck Depression Inventory of Schneiderian first rank symptoms, 24\% depression rate were reported among schizophrenic patients $^{7}$. It has found in acute Schizophrenics $16.66 \%$ of patients are having minimal depression which reflects no depression in the subjects, $36.66 \%$ are mild, $40 \%$ are moderate and $6.66 \%$ are having severe depression.

In chronic Schizophrenics, $33.33 \%$ of patients are having minimal depression which reflects no depression in the subjects, $16.66 \%$ are mild, $36.66 \%$ are moderate and $13.33 \%$ are having severe level of depression.

Difference between acute and chronic Schizophrenics are significant, reveals that both groups are having different level of depression.

Results reflect that depression is an integral feature of Schizophrenics and distinct domain in Schizophrenics.
Table B2: Item wise distribution of patients with acute and chronic Schizophrenia on Beck Depression Inventory

\begin{tabular}{|c|c|c|c|c|c|c|}
\hline \multirow{2}{*}{ Item } & & \multicolumn{4}{|c|}{ No of Subjects on Statements } & \multirow[b]{2}{*}{ 䜦 莺 } \\
\hline & & 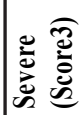 & 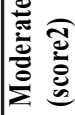 & 记 & 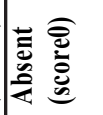 & \\
\hline \multirow{2}{*}{ A. Mood } & Acute & 2 & 13 & 12 & 3 & 6.29 \\
\hline & Chronic & 4 & 10 & 6 & 10 & NS* \\
\hline \multirow{2}{*}{ B. Pessimism } & Acute & 2 & 6 & 11 & 11 & 1.07 \\
\hline & Chronic & 2 & 7 & 8 & 13 & NS* \\
\hline \multirow{2}{*}{ C. Sense of failure } & Acute & 8 & $\mathbf{0}$ & 11 & 11 & 12.98 \\
\hline & Chronic & 5 & 10 & 5 & 10 & $S^{*}$ \\
\hline \multirow{2}{*}{ D. Lack of satisfaction } & Acute & 4 & 5 & 10 & 11 & 2.98 \\
\hline & Chronic & 3 & 2 & 16 & 9 & NS* \\
\hline \multirow{2}{*}{ E. Guilt feeling } & Acute & 2 & 10 & 6 & 12 & 2.09 \\
\hline & Chronic & 1 & 6 & 9 & 14 & NS* \\
\hline \multirow{2}{*}{ F. Sense of punishment } & Acute & 2 & 13 & 6 & 9 & 3.3 \\
\hline & Chronic & 2 & 7 & 6 & 15 & NS* \\
\hline \multirow{2}{*}{ G.. Self hate } & Acute & 4 & 5 & 13 & 8 & 4.87 \\
\hline & Chronic & 1 & 8 & 8 & 13 & NS* \\
\hline \multirow{2}{*}{ H. Self Accusation } & Acute & 1 & 7 & 9 & 13 & 4.28 \\
\hline & Chronic & 0 & 15 & 7 & 8 & NS* \\
\hline \multirow{2}{*}{ I. Self punitive wishes } & Acute & 2 & 6 & 5 & 17 & 2.71 \\
\hline & Chronic & 0 & 7 & 7 & 16 & NS* \\
\hline \multirow{2}{*}{ J. Crying spells } & Acute & 4 & 3 & 14 & 9 & 9.97 \\
\hline & Chronic & 3 & 5 & 5 & 17 & $\mathrm{~S}^{*}$ \\
\hline \multirow{2}{*}{ K. Irritability } & Acute & 2 & 6 & 4 & 18 & 4.66 \\
\hline & Chronic & 4 & 1 & 6 & 19 & NS* \\
\hline \multirow{2}{*}{ L. Social withdrawals } & Acute & 1 & 3 & 10 & 16 & 13.09 \\
\hline & Chronic & 3 & 5 & 9 & 13 & $\mathrm{~S}^{*}$ \\
\hline \multirow{2}{*}{ M.Indicisiveness } & Acute & 5 & 1 & 4 & 20 & 7.27 \\
\hline & Chronic & 1 & 7 & 4 & 18 & NS* \\
\hline \multirow{2}{*}{ N. Body image } & Acute & 5 & 2 & 4 & 19 & 5.54 \\
\hline & Chronic & 1 & 5 & 8 & 16 & NS* \\
\hline \multirow{2}{*}{ 0. Work inhibition } & Acute & 1 & 1 & 6 & 22 & 19.28 \\
\hline & Chronic & $\mathbf{0}$ & 2 & 12 & 16 & $S^{*}$ \\
\hline \multirow{2}{*}{ P. Self disturbance } & Acute & 2 & 1 & 4 & 23 & 5.28 \\
\hline & Chronic & 4 & 6 & 3 & 17 & NS* \\
\hline \multirow{2}{*}{ Q. Fatigability } & Acute & 1 & 8 & 8 & 13 & 2.13 \\
\hline & Chronic & 2 & 4 & 11 & 13 & NS* \\
\hline \multirow{2}{*}{ R. Loss of appetite } & Acute & 0 & 5 & 4 & 21 & 7.32 \\
\hline & Chronic & 1 & 5 & 4 & 20 & NS* \\
\hline \multirow{2}{*}{ S. Loss of weight } & Acute & 0 & 0 & 4 & 26 & 3.83 \\
\hline & Chronic & 1 & 3 & 3 & 23 & NS* \\
\hline \multirow{3}{*}{ T. Somatic preoccupation } & Acute & 1 & 4 & 5 & 20 & 1.35 \\
\hline & Chronic & 1 & 3 & 4 & 22 & NS* \\
\hline & Acute & 1 & 6 & 15 & 8 & 2.06 \\
\hline
\end{tabular}

$\mathrm{NS}^{*}=$ not significant at .05 level $\mathrm{S}^{*}=$ significant at .05 level 
The above table shows that there is significant difference between the groups with respect to sense of failure, crying spells, social withdrawal, and in work inhibition items.

Results reflect that the depressive symptoms are quantitatively and qualitatively among the most important characteristics of Schizophrenics.

Table C: Level of anxiety in Acute \& Chronic Schizophrenics

\begin{tabular}{|l|l|l|l|l|}
\hline \multirow{2}{*}{ Group } & \multicolumn{2}{|l|}{ Level of Anxiety } & \multirow{2}{*}{$\begin{array}{l}\text { Chi- } \\
\text { square }\end{array}$} \\
\cline { 2 - 4 } & $\begin{array}{l}\text { Low } \\
\text { Anxiety }\end{array}$ & $\begin{array}{l}\text { Average } \\
\text { Anxiety }\end{array}$ & $\begin{array}{l}\text { High } \\
\text { Anxiety }\end{array}$ & \\
\hline Acute & $0(0 \%)$ & $13(43.33 \%)$ & $17(56.66 \%)$ & $2.10, \mathrm{NS}^{*}$ \\
\hline Chronic & $2(6.66 \%)$ & $13(43.33 \%)$ & $15(50.00 \%)$ & \\
\hline
\end{tabular}

NS $*=$ not significant at .05 level

The above table shows that there is no significant difference between the groups with respect to their anxiety level. In acute Schizophrenics group 43.33\% had average level of anxiety, $56.66 \%$ of patients had high level of anxiety and in chronic Schizophrenics group $43.33 \%$ had average level of anxiety, $50 \%$ of patients had high level of anxiety.

Statistically, there is no significant difference between acute and chronic Schizophrenia in so far as their level of anxiety is concerned. Thus both the groups have same level of anxiety.

Table C.2: Overt and covert of anxiety in Acute \& Chronic Schizophrena

\begin{tabular}{|l|l|l|l|l|}
\hline \multirow{2}{*}{ Group } & \multicolumn{3}{|l|}{ Dimension of Anxiety } & \multirow{2}{*}{$\begin{array}{l}\text { Chi- } \\
\text { square }\end{array}$} \\
\cline { 2 - 4 } & $\begin{array}{l}\text { Mainly } \\
\text { Overt }\end{array}$ & $\begin{array}{l}\text { Mainly } \\
\text { Covert }\end{array}$ & Mixed & \\
\hline Acute & $14(46.66 \%)$ & $12(40.00 \%)$ & $4(13.33 \%)$ & $.292, \mathrm{NS}^{*}$ \\
\hline Chronic & $12(40 \%)$ & $13(43.33 \%)$ & $5(16.66 \%)$ & \\
\hline
\end{tabular}

NS*=not significant at .05 level

The above table shows that there is no significant difference between the groups with respect to overt and covert anxiety.
The scale measures two type of anxiety, overt and covert anxiety. Covert anxiety which measures unrealised anxiety and overt anxiety which measures realised anxiety. For acute group, $46.66 \%$ cases are showing mainly overt anxiety, $40 \%$ are showing mainly covert anxiety and $13.33 \%$ are showing equal level of overt and covert anxiety.

For chronic group, $40 \%$ cases were had mainly overt anxiety, $43.33 \%$ had mainly covert anxiety and $16.66 \%$ had equal level of overt and covert anxiety.

Table D1: Level of life satisfaction in Acute \& Chronic Schizophrenia

\begin{tabular}{|l|l|l|l|l|}
\hline \multirow{2}{*}{ Group } & \multicolumn{2}{|l|}{ Level of Life Satisfaction } & \multirow{2}{*}{$\begin{array}{l}\text { Chi- } \\
\text { square }\end{array}$} \\
\cline { 2 - 5 } & Low & Average & High & \\
\hline Acute & $3(10.00 \%)$ & $13(43.33 \%)$ & $14(46.66 \%)$ & $10.184, \mathrm{~S}^{*}$ \\
\hline Chronic & $7(23.33 \%)$ & $20(66.66 \%)$ & $3(10.00 \%)$ & \\
\hline
\end{tabular}

$\mathrm{S} *=$ Significant at .05 level

The above table shows that there is significant difference between the groups with respect to their level of life satisfaction.

In the present study, out of 30 acute cases of schizophrenia only 3 cases i.e. about $10 \%$ of total cases were not satisfied with their life. Whereas 7 out of 30 cases of chronic schizophrenia which is about $23.33 \%$ were not satisfied with their life and both the groups statistically differ significantly in their level of life satisfaction.

On the other hand out of 30 acute cases 14 cases i.e. about $46.66 \%$ of total cases was highly satisfied with their life. Whereas only 3 out of 30 cases of chronic schizophrenia which is about $10 \%$ was highly satisfied.

Difference between acute and chronic Schizophrenics on level of life satisfaction was significant. It has been found that acute schizophrenic reported more life satisfaction in comparison to chronic Schizophrenics.

It is concluded that better understanding of the combining effects of psychopathology and 
psychosocial factors on subjective life satisfaction will be beneficial for effective intervention and rehabilitation.

\section{CONCLUSION:}

The conclusion of this study can be summarized as follows:

- There is significant difference between level of depression in acute and chronic schizophrenia.

- There is no significant difference between level of anxiety in acute and chronic schizophrenia

- There is significant difference between level of life satisfaction in acute and chronic schizophrenia

\section{REFERENCES}

1. Knights, A. \& Hirch, S.R., (1981) 'Revealed' depression and drug treatment of schizophrenia. Archives of General Psychiatry, 38, 806-811.

2. Birchwood, M., Iqbal, Z., Chadwick, P., Trower, P. (2000), Ontogeny of post-psychotic depression. British Journal of Psychiatry, 177, 516-21.

3. Leff, J., Tress, K., Edqards, B. (1988). The Clinical course of depressive symptoms in schizophrenia. Schizophrenia Research, 1, 25-30.

4. Hirsh, S.R., Jolley, A., Barnes, T., (1990). Are depressive symptoms part of the schizophrenic syndrome? In: DeLisi, L.E., (Ed). Depression in schizophrenia. American Psychiatric Press, Washington D.C., pp. 27-37.

5. Strian, F. \& Klicpera (1983). Anxiety in schizophrenia psychosis. European Archives of Psychology, 233, 247-257.

6. Alam, Q.G. \& Srivastva, R. (2001). Life Satisfaction Scale. (LSS). National Psychological corporation. 4/230, Kacheri Ghat, Agra.

7. Johnson, D.A.W. (1981). Depression in schizophrenia some observation on prevalence, etiology and treatment. Acta Psychchiatrica Scandinavica, 63(Suppl. 291), 137-144. 